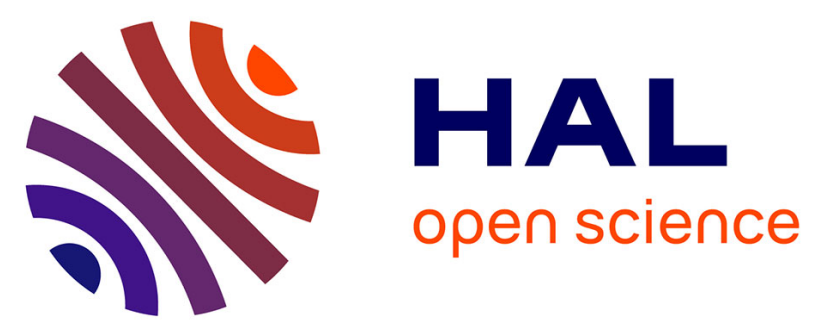

\title{
Hybrid solar cells based on thin-film silicon and P3HT
}

Pierre-Jean Alet, Serge Palacin, Pere Roca I Cabarrocas, Billel Kalache, Muriel Firon, Rémi de Bettignies

\section{To cite this version:}

Pierre-Jean Alet, Serge Palacin, Pere Roca I Cabarrocas, Billel Kalache, Muriel Firon, et al.. Hybrid solar cells based on thin-film silicon and P3HT. European Physical Journal: Applied Physics, 2007, 36, pp.231. 10.1051/epjap:2006145 . cea-00301919

\section{HAL Id: cea-00301919 https://hal-cea.archives-ouvertes.fr/cea-00301919}

Submitted on 25 Jul 2008

HAL is a multi-disciplinary open access archive for the deposit and dissemination of scientific research documents, whether they are published or not. The documents may come from teaching and research institutions in France or abroad, or from public or private research centers.
L'archive ouverte pluridisciplinaire HAL, est destinée au dépôt et à la diffusion de documents scientifiques de niveau recherche, publiés ou non, émanant des établissements d'enseignement et de recherche français ou étrangers, des laboratoires publics ou privés. 


\title{
Hybrid solar cells based on thin-film silicon and P3HT
}

\section{A first step towards nano-structured devices}

\author{
P.-J. Alet ${ }^{1,2, a}$, S. Palacin ${ }^{1}$, P. Roca I Cabarrocas ${ }^{2}$, B. Kalache², M. Firon ${ }^{3}$, and R. de Bettignies ${ }^{3}$ \\ 1 Laboratoire de chimie des surfaces et interfaces, CEA/DSM/DRECAM/SPCSI/LCSI, Centre de Saclay, Bât. 466, \\ 91191 Gif-sur-Yvette Cedex, France \\ 2 Laboratoire de physique des interfaces et couches minces, École polytechnique, UMR 7647, 91128 Palaiseau Cedex, France \\ 3 Laboratoire des composants pour le solaire, CEA/DRT/LITEN/LCS, Bât. 451, 91191 Gif-sur-Yvette Cedex, France
}

Received: 25 July 2006 / Received in final form: 17 October 2006 / Accepted: 24 October 2006 Published online: 10 January 2007 - (C) EDP Sciences

\begin{abstract}
Hybrid concepts based on a nanoscale combination of organic and inorganic semiconductors are a promising way to enhance the cost efficiency of solar cells through a better use of the solar spectrum, a higher aspect ratio of the interface, and the good processability of polymers. A new type of solar cells has been investigated. It is based on a heterojunction between regio-regular poly(3-hexylthiophene) as an organic electron donor and silicon as an inorganic electron acceptor. In a first step towards nanostructured devices, cells made of flat thin films of these materials have been studied as a model case of the heterojunction. The materials were characterized through ellipsometry and absorption spectroscopy. The devices were studied by means of their spectral response and their $I$ - $V$ characteristics. By combining these results, the contribution of each layer and the mechanisms of photocurrent generation are explained. The best cells to-date show a power conversion efficiency of $1.6 \%$ under AM 1.5 illumination, with a $V_{o c}$ of $0.704 \mathrm{~V}$ and a $J_{s c}$ of $4.22 \mathrm{~mA} / \mathrm{cm}^{2}$.
\end{abstract}

PACS. 81.07.Pr Organic-inorganic hybrid nanostructures - 73.50.Pz Photoconduction and photovoltaic effects

\section{Introduction}

Enhancing the separation of charge carriers - to prevent them from recombining - is a major means to improve the efficiency of solar cells. As this separation occurs at the interface between two materials, a good way to improve it is to increase the ratio between the area and the volume.

Several types of devices based on this principle have been proposed. With all-organic interpenetrated networks of electron donors (e.g. $\mathrm{P}_{3} \mathrm{HT}^{1}$ ) and acceptors (e.g. PCBM), efficiencies as high as $3.8 \%$ have been reported [1]. Bulk heterojunctions between polymers and inorganic nanoparticles lead to efficiencies of $1.8 \%$ (with MDMO-PPV and branched CdSe nanoparticles [2]). Devices, where nanostructured materials are directly grown on the substrate as proposed by Coakley et al. [3], would additionally bring an electrically continuous path from the active interface to the electrodes.

In most devices based on this concept, the nanostructured part is the electrode, which does not actively contribute to the photocurrent. Yet one could imagine

\footnotetext{
* This paper has been presented at "ECHOS06", Paris, $28-30$ juin 2006.

a e-mail: pierre-jean.alet@polytechnique.edu

1 poly(3-hexylthiophene).
}

devices where this part is photoactive, too. Good candidates could be cells made of silicon nanowires - as an inorganic electron acceptor - grown on a transparent conductive oxide and regio-regular P3HT [4] as an organic electron donor. In a first step towards these nanostructured hybrid cells, simplified ones, which are based on a planar heterojunction between P3HT and thin-film silicon, have been studied. It was thus possible to investigate the organic/inorganic junction independently of the actual shape of the layers.

The fabrication and characterization of these devices are presented here. It is shown that this junction can be valuable for photovoltaic conversion, and the mechanisms of photocurrent generation are explained. Finally, some guidelines for the improvement of devices based on these materials are given.

\section{Experimental section}

\subsection{Device fabrication}

The devices are made of stacked thin films deposited on glass substrates covered with ITO (Indium Tin Oxide). At first, substrates are etched using a mixture of nitric acid and chlorhydric acid to partly remove ITO and cleaned 
Table 1. Typical parameters for deposition of silicon layers by PECVD.

\begin{tabular}{lccccc}
\hline Layer & \multicolumn{5}{c}{ Flow rates (sccm) } \\
& $\begin{array}{c}\text { Pressure } \\
\text { (mtorr) }\end{array}$ & $\mathrm{SiH}_{4}$ & $\mathrm{H}_{2}$ & $\mathrm{PH}_{3}$ & $\mathrm{RF}$ power \\
\hline$\mu \mathrm{c}-\mathrm{Si}(\mathrm{n})$ & 2700 & 3 & 200 & & 11 \\
$\mu \mathrm{c}-\mathrm{Si}(\mathrm{i})$ & 2700 & 3 & 200 & 0 & 11 \\
$\mathrm{a}-\mathrm{Si}: \mathrm{H}(\mathrm{n})$ & 50 & 50 & 0 & 1 & 1 \\
$\mathrm{a}-\mathrm{Si}: \mathrm{H}(\mathrm{i})$ & 150 & 50 & 100 & 0 & 3 \\
\hline
\end{tabular}

by ultrasonication in acetone, isopropanol and de-ionized water baths. Electric contacts made of chromium (10 nm) and gold $(40 \mathrm{~nm})$ are then evaporated by Joule effect under high vacuum (around $5 \times 10^{-7}$ mbar) in a BOC Edwards Auto 306 Vacuum Coater.

Two sets of devices were prepared. For the first type, silicon $^{2}$ is directly grown on ITO by PECVD (Plasma Enhanced Chemical Vapor Deposition) at a temperature of $200{ }^{\circ} \mathrm{C}$ and under the conditions given in Table 1. P3HT was purchased from Sigma-Aldrich and not modified. It is dissolved in chlorobenzene before being spincoated on top of silicon. The concentration used for most samples is $20 \mathrm{~g} / \mathrm{L}$, which leads to thicknesses ranging from 60 to $70 \mathrm{~nm}$. The samples are then annealed for $5 \mathrm{~min}$ at $110{ }^{\circ} \mathrm{C}$ to evaporate the solvent. After deposition of the top electrodes, the structure of the devices is: ITO/a-Si:H(n)/a-Si:H(i)/P3HT/metal or ITO/a$\mathrm{Si}: \mathrm{H}(\mathrm{n}) / \mu \mathrm{c}-\mathrm{Si}(\mathrm{i}) / \mathrm{P} 3 \mathrm{HT} / \mathrm{metal}$. Palladium is preferably used because it has almost the same work function as gold ${ }^{3}$ $\left(\Phi_{\mathrm{Pd}}=5.2 \mathrm{eV}\right.$ and $\left.\Phi_{\mathrm{Au}}=5.1 \mathrm{eV}\right)$ but its deposition leads to fewer short-circuits.

For the second type of devices, silicon is grown on P3HT to avoid the presence of native oxide at the interface between the two materials and to make illumination through P3HT possible. In order to fit the work function of the bottom electrode to the HOMO (Highest Occupied Molecular Orbital) level of P3HT and to enhance the adhesion between the two materials, an intermediate layer of PEDOT:PSS (poly(3,4-ethylenedioxythiophene):poly(styrenesulfonate)) is spin coated on ITO. The samples are then annealed for an hour at around $120^{\circ} \mathrm{C}$, and dissolved P3HT is spin-coated on top of it. After another annealing $\left(5 \mathrm{~min}\right.$ at $\left.110^{\circ} \mathrm{C}\right)$, amorphous silicon is deposited by PECVD at $80^{\circ} \mathrm{C}$; the conditions used for this deposition are also summarized in Table 1 . Finally, $50 \mathrm{~nm}$-thick top electrodes made of aluminium are evaporated. The structure of these devices is: ITO/PEDOT/P3HT/a-Si:H(i)/ a-Si:H(n)/Al.

The structure of the two types of devices is summarized in Figure 1. The area of the cells $-28 \mathrm{~mm}^{2}-$ is defined by the size of the top electrodes.

\footnotetext{
${ }^{2}$ Intrinsic, n-doped microcrystalline silicon and hydrogenated amorphous silicon are abbreviated to $\mu \mathrm{c}-\mathrm{Si}(\mathrm{i}), \mu \mathrm{c}-$ $\mathrm{Si}(\mathrm{n})$, a-Si:H(i) and a-Si:H(n), respectively.

${ }^{3}$ Gold is used as top electrode with P3HT and other organic semiconductors by most authors and was also used at the beginning of this study.
}
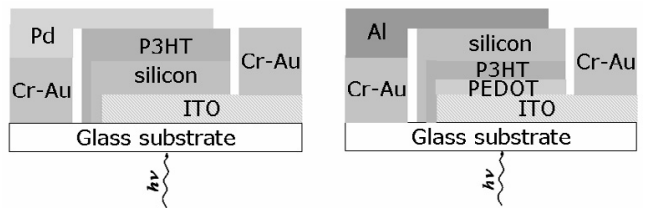

Fig. 1. Schematic side-view of the type I (left) and II (right) devices.

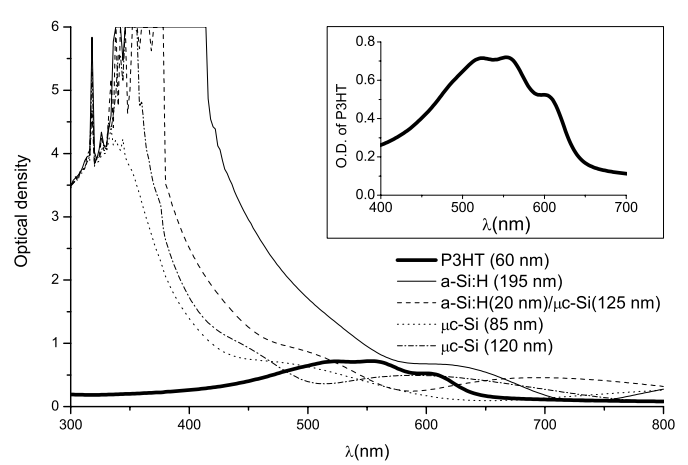

Fig. 2. Absorption spectra of materials used in the devices (inset: absorption spectrum of P3HT between $400 \mathrm{~nm}$ and $700 \mathrm{~nm})$.

The evaporation of metals, every step involving P3HT (dissolution, spin-coating and annealing) and $I-V$ measurements under AM 1.5 illumination are made in an MBraun clean glovebox under nitrogen atmosphere.

\subsection{Characterization}

Optical densities of materials are measured with a Perkin Elmer UV/Vis/NIR Lambda 19 spectrometer. Ellipsometry spectra are obtained with a Uvisel Jobin-Yvon Horiba system and processed using DeltaPsi2 software. The thickness of the silicon layers is determined using ellipsometry spectra and that of P3HT films is measured with an Alpha Step IQ surface profiler. AM 1.5 illumination at $100 \mathrm{~mW} / \mathrm{cm}^{2}$ over an area of about $10 \times 10 \mathrm{~cm}^{2}$ is provided by a KHS SolarConstant solar simulator. $I-V$ characteristics under illumination are measured with a computer-run Keithley 2400 SourceMeter. $I-V$ curves in dark at various temperatures are measured under primary vacuum (about 1 mbar) in a homemade cryogenic system.

\section{Results and discussion}

\subsection{Materials}

Absorption spectra of several kinds of silicon layers and of a $60 \mathrm{~nm}$-thick layer of P3HT are compared in Figure 2. In that case, amorphous silicon absorbs more light than microcrystalline silicon for $400 \mathrm{~nm} \leq \lambda \leq 500 \mathrm{~nm}$, which 


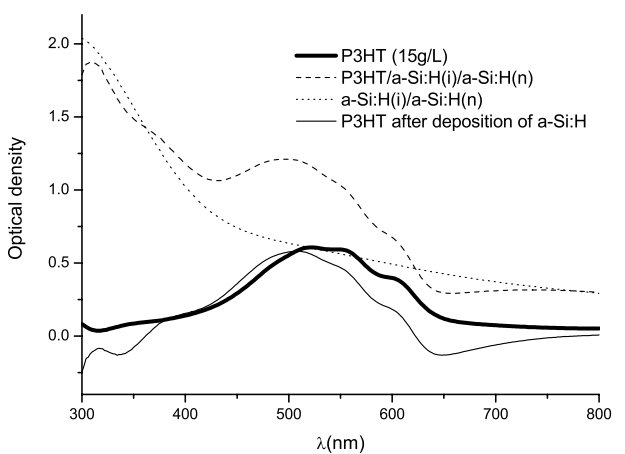

Fig. 3. Absorption spectra of layers in a device of type II.

is part of the absorption range of P3HT. This partly explains the low level of photocurrent when amorphous silicon is used as the intrinsic layer. Nevertheless, the respective absorption maxima of the polymer and silicon are clearly separated, so the devices should make an efficient use of the solar spectra when the silicon layer is thin enough. Moreover, amorphous silicon is used in most samples because its higher bandgap allows to reach a higher $V_{o c}$ and to separate the charge carriers more efficiently. It should be noted that for layer thicknesses of the same order of magnitude, the optical density of P3HT is much lower than that of silicon, so much more of the incident light reaches the interface between the two materials when the devices are illuminated through $\mathrm{P} 3 \mathrm{HT}$ rather than through silicon.

The optical density of the layers of type II devices (ITO/PEDOT/P3HT/Si/Al) are shown in Figure 3. The absorption spectra of P3HT after the deposition of silicon was computed by subtracting that of amorphous silicon deposited on glass to that of the whole active layers (PEDOT/P3HT/a-Si:H(i)/a-Si:H(n)); all silicon layers were deposited in the same run. The difference of optical density with pristine P3HT can be explained by the fact that the latter was deposited on glass instead of PEDOT, so the thickness of the layer is higher. Nevertheless, the shapes of the two curves are quite similar, which shows that P3HT is not chemically affected by the top deposition of silicon at low temperature.

The thickness of P3HT layers strongly depends on the surface state of the substrate. For example, for a given concentration of the solution $(15 \mathrm{~g} / \mathrm{L})$, the spin-coating of the polymer over two different films of a-Si:H (one being much more hydrogenated than the other) leads to layer thicknesses of $35 \mathrm{~nm}$ and $60 \mathrm{~nm}$, respectively. A thorough study of this phenomenon is under way.

\subsection{Devices}

\subsubsection{I-V Characteristics}

As shown in Figure 4, the devices generally have a good rectifying behavior: $\frac{I_{\mathrm{On}}}{I_{\mathrm{Off}}} \simeq 10^{5}$ at $\pm 0.7 \mathrm{~V}$ at room temper-

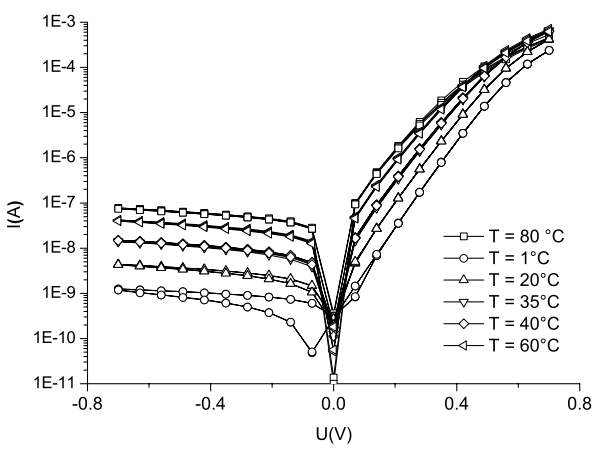

Fig. 4. $I$ - $V$ characteristics in the dark at various temperatures of a cell made of ITO/a-Si:H(n)/a-Si:H(i)/P3HT/Au.

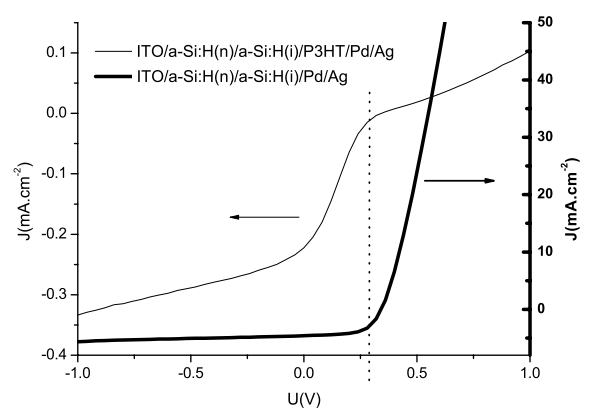

Fig. 5. $I-V$ characteristics of a Schottky cell based on a-Si:H (bold) and of one of structure ITO/a-Si:H(n)/a$\mathrm{Si}: \mathrm{H}(\mathrm{i}) / \mathrm{P} 3 \mathrm{HT} / \mathrm{Pd}$ (light), the silicon on both devices being prepared in the same run.

ature ${ }^{4}\left(20^{\circ} \mathrm{C}\right)$. Yet on some of them this is limited by a shoulder in the characteristics under direct polarization, which clearly comes from the polymer layer. Indeed, as shown in Figure 5, the shoulder is visible on the characteristics of the whole device, whereas it is not apparent on the characteristics of a Schottky cell made with the same batch of amorphous silicon (a-Si:H(n)/a-Si:H(i)). Nevertheless, it is not clear yet whether this comes from the interface between silicon and P3HT or from the one between P3HT and the metal electrode.

The main limitation to the efficiency of these cells is the photocurrent, which ranges from $0.01 \mathrm{~mA} / \mathrm{cm}^{2}$ to $4 \mathrm{~mA} / \mathrm{cm}^{2}$. The $V_{o c}$ reaches $0.7 \mathrm{~V}$, which is almost twice as much as the Schottky cell where the only photoactive material is a-Si:H(n) and a-Si:H(i). Yet it should be noted that there is no improvement of the $V_{o c}$ with respect to this Schottky cell when a shoulder is visible. Finally, the fill factor being up to 0.6 , the best energy conversion efficiency to-date is $1.6 \%$.

\footnotetext{
4 This ratio is generally limited by the current density in direct polarization and provides thus a good information on the conductivity of the materials; in addition, the better the ratio, the higher $J_{s c}$.
} 


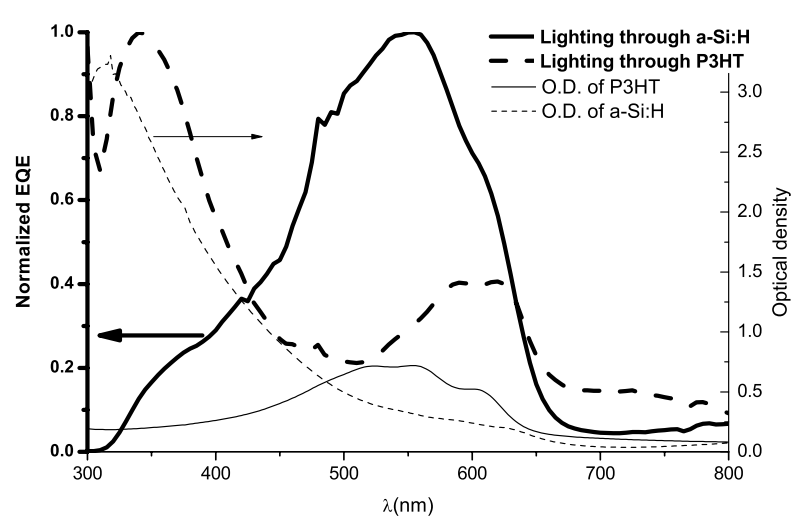

Fig. 6. Spectral response (bold) of the device ITO/a$\mathrm{Si}: \mathrm{H}(\mathrm{n}) / \mathrm{a}-\mathrm{Si}: \mathrm{H}(\mathrm{i}) / \mathrm{P} 3 \mathrm{HT} / \mathrm{Pd}$ when illuminated through silicon (plain) or P3HT (dashed line) and absorption spectra (light) of P3HT (plain) and amorphous silicon (dotted line).

\subsubsection{Spectral response}

As can be seen in Figure 6, most of the photocurrent is generated within the absorption range of $\mathrm{P} 3 \mathrm{HT}$ when the incident light first goes through ITO and silicon. It is symbatic generation, i.e. the peaks in the absorption spectrum of $\mathrm{P} 3 \mathrm{HT}$ and those in the spectral response are in phase. This shows that the faster the photons are absorbed, the more they contribute to photocurrent. Hence the actual separation of charge carriers happens at the interface with silicon, which is here the first side of the P3HT layer to be illuminated.

On the contrary, when the incident light first goes through the top electrode and P3HT, two separate peaks clearly appear in the spectral response. Each of it corresponds to the absorption maximum of a-Si:H and P3HT, respectively. Moreover, the charge carrier generation in P3HT appears to be antibatic, i.e. local maxima in the absorption spectrum of P3HT correspond to local minima in the spectral response, and conversely. This shows that photons absorbed faster contribute less to the photocurrent. Besides, it must be kept in mind that only excitons generated within a distance to the interface shorter than their diffusion length in P3HT - around $5 \mathrm{~nm}[5]$ - can be separated and efficiently contribute to photocurrent. From those two facts it can be concluded that the dissociation of excitons generated in P3HT happens at the interface which lies further from the light source, i.e. the interface with silicon.

The curves presented here are normalized because, due to the absorption by the metal electrode, the value of the external quantum efficiency is about ten times smaller when the devices are illuminated through $\mathrm{Pd}$ and P3HT than in the other case.
Because of the high absorption coefficient of a-Si:H for wavelengths lower than $400 \mathrm{~nm}$ (about $7 \times 10^{7} \mathrm{~m}^{-1}$ ), the penetration length is about $10 \mathrm{~nm}$, which is much smaller than the total thickness of the silicon layer (50 nm). Most charge carriers are thus generated within this distance from the first interface reached by photons. Due to their low mobility in a-Si:H (typically $1 \mathrm{~cm}^{2} / \mathrm{Vs}$ for electrons and $3 \times 10^{-3} \mathrm{~cm}^{2} / \mathrm{Vs}$ for holes [6]), most of them recombine before being separated if separation does not occur at this interface.

In our case, silicon contributes efficiently to photocurrent when it is illuminated from its interface with P3HT, and not when light comes through ITO, which shows that, as for P3HT, the interface where carriers generated in a$\mathrm{Si}: \mathrm{H}$ are separated is the interface between the polymer and silicon.

\section{Conclusion}

P3HT actively contributes to the efficiency of cells based on a flat heterojunction between this polymer and thinfilm silicon: the solar spectrum is better used thanks to the separation between the respective absorption maxima of the two materials; the open-circuit voltage is increased with respect to cells made of similar silicon layers without P3HT. The separation of charge carriers actually occurs at the interface between the organic and inorganic semiconductors.

The global efficiency is limited by the low level of photocurrent, which is mainly due to the poor conductivity of both materials. Higher efficiencies could be reached if the cells were illuminated through P3HT rather than through silicon. This would require transparent enough metal electrodes for type I devices, or the improvement of amorphous silicon deposited at low temperature for type II devices.

\section{References}

1. R. De Bettignies, J. Leroy, M. Firon, C. Sentein, Synthetic Met. 156, 510 (2006)

2. B.Q. Sun, E. Marx, N.C. Greenham, Nano Letters 3, 961 (2003)

3. K.M. Coakley, Y.X. Liu, C. Goh, M.D. McGehee, MRS Bull. 30, 37 (2005)

4. T.A. Chen, X.M. Wu, R.D. Rieke, J. Am. Chem. Soc. 117, $233(1995)$

5. J.E. Kroeze, T.J. Savenije, M.J.W. Vermeulen, J.M. Warman, J. Phys. Chem. B 107, 7696 (2003)

6. J.B. Chévrier, Ph.D. thesis, Université de Paris VII, 1993 